\title{
Microsurgical Cisternostomy for Treating Critical Patients with Traumatic Brain Injury - An alternative Therapeutic Approach
}

\section{Cisternostomia microcirúrgica para o tratamento de pacientes críticos com lesões cerebrais traumáticas - Uma abordagem terapêutica alternativa}

\author{
Aline Lariessy Campos Paiva ${ }^{1}$ João Luiz Vitorino Araujo ${ }^{10}$ Renan Maximilian Lovato ${ }^{10}$ \\ José Carlos Esteves Veiga ${ }^{10}$ \\ ${ }^{1}$ Department of Neurosurgery, Faculdade de Ciências Médicas da \\ Santa Casa de São Paulo (FCMSCSP), São Paulo, SP, Brazil \\ Address for correspondence Aline Lariessy Campos Paiva, MD, \\ Irmandade da Santa Casa de Misericordia de Sao Paulo, Sao Paulo, SP, \\ Arq Bras Neurocir 2020;39(3):155-160. \\ Brazil (e-mail: lariessy@hotmail.com).
}

\begin{abstract}
Keywords

- cisternostomy

- traumatic brain injury

- decompressive craniectomy

- hydrodynamics

Introduction Traumatic brain injury (TBI) is a major cause of mortality around the world. Few advances regarding surgical approaches have been made in the past few years to improve its outcomes. Microsurgical cisternostomy is a well-established technique used in vascular and skull base surgery and recently emerges as a suitable procedure with lesser costs and morbidity when compared with decompressive craniectomy in patients with diffuse TBI. This study aims to describe the technique, indications, and limitations of cisternostomy and to compare it with decompressive craniectomy (DC).

Methods A prospective study is being conducted after obtaining approval of the local human ethics research committee. Once the inclusion and exclusion criteria are applied, the patients are submitted to microsurgical cisternostomy, pre and postoperative neurological status and brain computed tomography (CT) evaluation. A detailed review was also performed, which discusses diffuse TBI, DC, and cisternostomy for the treatment of TBI.

Results Two patients were submitted to cisternostomy after TBI and the presence of acute subdural hematoma and huge midline shift at admission computed tomography. The surgery was authorized by the family (the informed consent form was signed). Both patients evolved with a good recovery after the procedure, and had a satisfactory control brain CT. No further surgeries were required after the initial cisternostomy. Conclusions Cisternostomy is an adequate technique for the treatment of selected patients affected by diffuse TBI, and it is a proper alternative to $D C$ with lesser costs and morbidity, since a single neurosurgical procedure is performed. A prospective study is being conducted for a better evaluation and these were the initial cases of this new protocol.
\end{abstract}

received

June 25, 2019

accepted

December 2, 2019
DOI https://doi.org/

10.1055/s-0040-1701279.

ISSN 0103-5355.
Copyright $(2020$ by Thieme Revinter

Publicações Ltda, Rio de Janeiro, Brazil
License terms

(c) 9 (1) 


\section{Resumo}

\section{Palavras-chave \\ - cisternostomia \\ - traumatismo cranioencefalico \\ - craniectomia descompressiva \\ - hidrodinâmica}

Introdução O traumatismo crânio-encefálico (TCE) é causa importante de mortalidade em todo mundo. Poucos avanços em relação a abordagens cirúrgicas foram feitos nos últimos anos com o objetivo de melhorar seus desfechos. A cisternostomia microcirúrgica é uma técnica bem estabelecida usada nas cirurgias vasculares e de base de crânio e que recentemente surgiu como um procedimento com menos custos e menor morbidade quando comparada a craniectomia descompressiva (CD) para pacientes vítimas de TCE. O presente estudo objetiva descrever a técnica, as indicações e as limitações da cisternostomia e compará-la com a CD.

Métodos Um estudo prospectivo está sendo conduzido após obtenção de autorização do comitê local de ética em pesquisa. Após aplicados os critérios de inclusão e exclusão, os pacientes são submetidos à cisternostomia microcirúrgica, sendo avaliados o status neurológico e as tomografias computadorizadas (TCs) de crânio pré e pósoperatórias. Alem disso, uma revisão detalhada foi realizada considerando a discussão sobre TCE difuso, CD, e cisternostomia para o tratamento do TCE.

Resultados Dois pacientes foram submetidos a cisternostomia após TCE com presença de lesão difusa incluindo hematoma subdural agudo e desvio de linha média. A cirurgia foi autorizada pelas famílias (o termo de consentimento informado foi assinado). Os pacientes evoluíram com boa recuperação após o procedimento, e a TC pós-operatória satisfatória. Não foram necessárias outras cirurgias após a cisternostomia.

Conclusões A cisternostomia é uma técnica adequada para o tratamento de pacientes selecionados vítimas de TCE com lesão difusa, e representa uma alternativa à CD, com menos custos e menor morbidade. Um estudo prospectivo está sendo conduzido para melhor avaliação, e esses foram os resultados iniciais deste novo protocolo.

\section{Introduction}

Traumatic brain injury (TBI) has a high incidence and mortality index in all age groups and all around the world. It also has a huge economic impact, mainly in developing countries, because of its direct and indirect costs and, therefore, public health budget commitment. ${ }^{1}$ A Brazilian retrospective study has shown an elevated cost associated with decompressive craniectomy (DC) for TBI. ${ }^{2}$ In the past decades, the incidence of trauma has significantly increased, and it is predicted that in few years it will surpass the incidence of some chronic conditions, such as vascular diseases. ${ }^{3}$ The importance of this theme is clear; nevertheless, few advances have been made in the last years, especially regarding neurosurgical approaches. In many countries, trauma neurosurgery did not have significant advances ${ }^{3}$ when it comes to trying to improve the outcomes and minimize the costs.

The knowledge of the mechanism of TBIs helps to understand the pathophysiology of these lesions and how to improve the therapeutic approaches. Traumatic brain injuries can be focal or diffuse. For focal lesions, there are detailed protocols describing intensive care unit (ICU) management and surgery indication according to the type, size, and topography of the injury. However, there are some controversies about the treatment of diffuse injuries. ${ }^{1}$ Considering surgical treatment, DC has been used in the past decades, although some large trials have not shown real benefits in the outcomes, ${ }^{4,5}$ and, besides, these patients required further surgeries to restore the normal brain hydrodynamic. ${ }^{6}$ Thus, DC is associated with elevated costs and few benefits. ${ }^{2}$

In this context, a well-defined technique, previously used in skull base and vascular surgeries, has been proposed to improve cerebrospinal fluid (CSF) flow, brain hydrodynamic and avoid DC. ${ }^{1}$ Cisternostomy is a technique in which the basal cisternae are opened, thus helping brain relaxation and, consequently, eliminating the need for DC. It is performed in patients with moderate or severe TBI and diffuse injuries who would classically be submitted to DC.

\section{Methods}

A research project was developed, evaluated and approved by the local human ethics research committee. It was also registered at the Plataforma Brasil database. All study procedures were in accordance with the ethical standards of the institutional and national research committee and with the 1964 Helsinki declaration and its later amendments or comparable ethical standards.

This is a prospective study in which patients affected by $\mathrm{TBI}$, considering the inclusion and exclusion criteria, are submitted to cisternostomy as the main neurosurgical procedure. The initial results are described in this paper, and an extensive review about diffuse TBI, DC and cisternostomy is also performed. This protocol is still being applied for a bigger evaluation. 
The inclusion criteria are patients between 18 and 70 years without severe systemic compromise and with diffuse TBI and classic indication for DC. A consent form was signed by the legal responsible, and the procedure performed within a maximum of 6 hours after emergency room (ER) admission. The pre and postoperative neurological exam and computed tomography (CT) were evaluated.

An extensive literature review considering the terms cisternostomy, traumatic brain injury, DC was conducted.

\section{Results}

After the local ethics committee approval, two patients were selected for cisternostomy, and they are described below.

\section{Case 1}

A 20-year-old male patient fell off a height of $3 \mathrm{~m}$ and was associated to TBI. He was admitted to the neurosurgical emergency department presenting with a Glasgow coma scale (GCS) of 12 and isochoric pupils, incapable of providing further information about his past medical history. He was evaluated according to Advanced Trauma Life Support (ATLS) protocol, and no other lesions were found. On his admission brain CT, a left acute subdural hematoma (ASH) with important midline shift was observed (- Fig. 1). The Zunkeller index was greater than $5 \mathrm{~mm}$. In this context, a microsurgical cisternostomy (-Fig. 2) was proposed and performed within the first 6 hours after admission. The hematoma was drained during surgery; however, despite this, the brain remained swollen. Because of this, microsurgical technique for opening the basal cisternae and the lamina terminalis was performed. After this, a proper

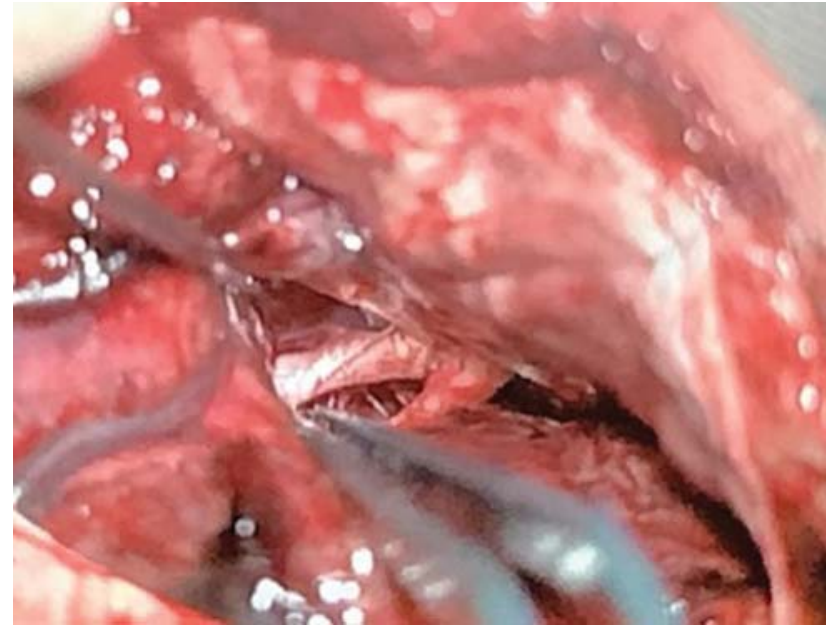

Fig. 2 Opticocarotid microsurgical cisterna opening - Case 1.

brain relaxation and edema decrease could be observed. Therefore, there was no need for a DC. The patient had a good recovery and was alert on the first postoperative day, with GCS of 15 and an adequate postoperative brain CT (-Fig. 1), without midline shift. He was discharged a few days after with a Glasgow outcome scale (GOS) of 5.

\section{Case 2}

A 69-year-old female patient presented to the neurosurgical emergency department after a fall from her own height and sudden unconsciousness. She arrived to the hospital with anisocoric (left $>$ right) pupils, with a GCS of 3 and under mechanical ventilation. She did not have other systemic

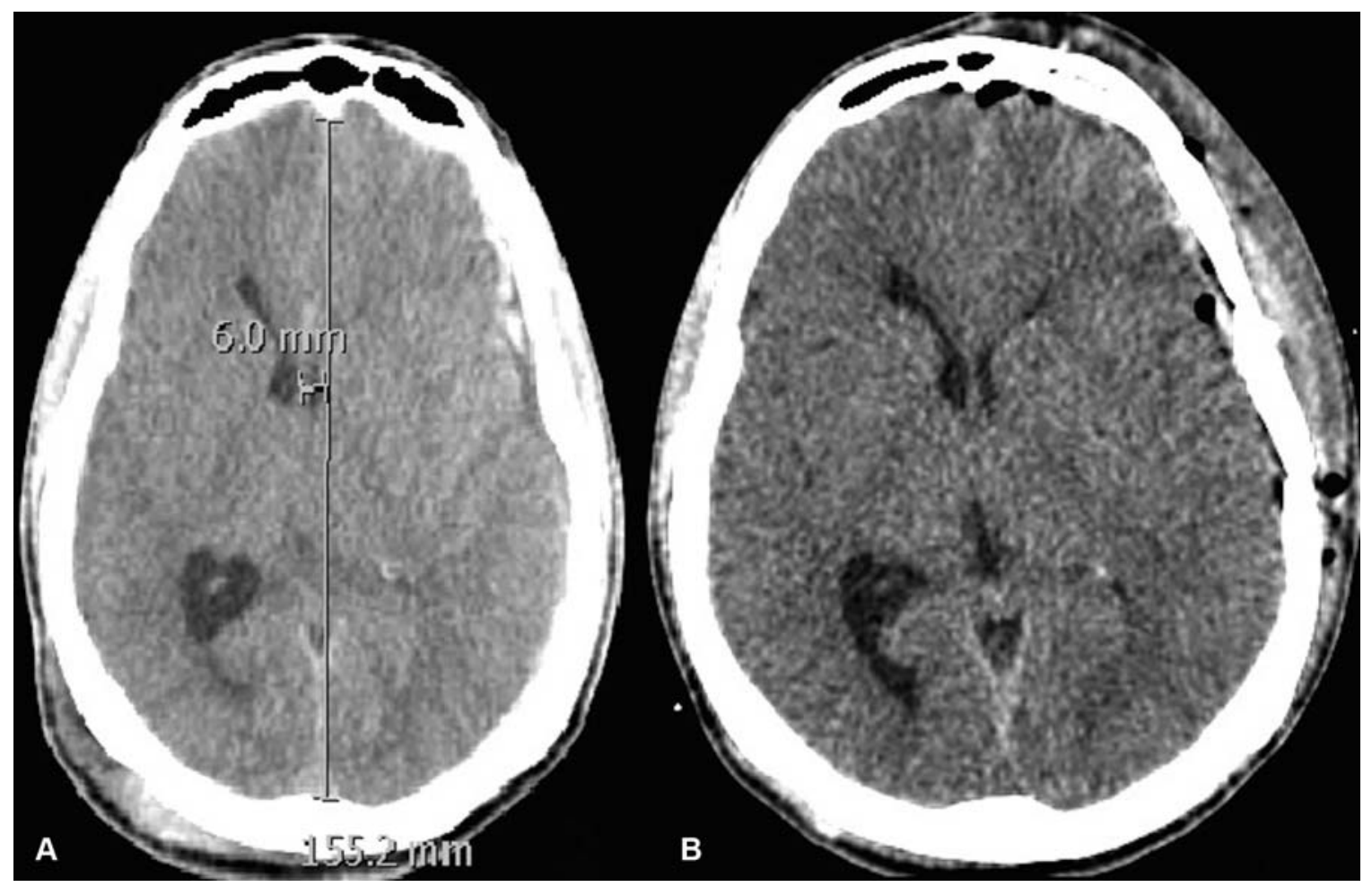

Fig. 1 (A) Admission axial brain computed tomography revealing a left subdural hematoma and brain swelling with midline shift; (B) 24-hour postoperative computed tomography revealing swelling reduction and no midline deviation. 
lesions after evaluation by the ATLS protocol. On her past medical history, it could be noticed that she was previously submitted to a ruptured aneurysm clipping surgery at the same hospital and required a ventriculoperitoneal shunt. After this, she remained with neurological sequelae, especially concerning her cognitive status. She also used drugs for blood hypertension and acetylsalicylic acid due to a previous stroke.

On her admission brain $\mathrm{CT}$, a massive ASH with midline shift (-Fig. 3) and a Zunkeller index greater than $5 \mathrm{~mm}$ were observed. She underwent a cisternostomy within less than 6 hours after admission ( - Fig. 4). The hematoma was drained during surgery; however, despite this, the brain remained with noticeable swelling and transcalvarial herniation. Therefore, a microsurgical cisternostomy was proposed through the opening of the basal cisternae and the lamina terminalis. After this it could be noticed a proper brain relaxation, edema decrease and herniation resolution. There was no need for skull removal through DC. She had a slower recovery when compared with the pilot case; however, her postoperative brain CT showed a good surgical result ( - Fig. 3 ) and she was discharged a month after the initial procedure with a GOS of 4 and with no need for further surgery.

No other neurosurgical procedures were required for either patient, and they had satisfactory recovery, evaluated through GOS and postoperative CT.

\section{Discussion}

Traumatic brain injury is a major cause of morbidity and mortality, especially in developing countries. ${ }^{2}$ Direct traumas

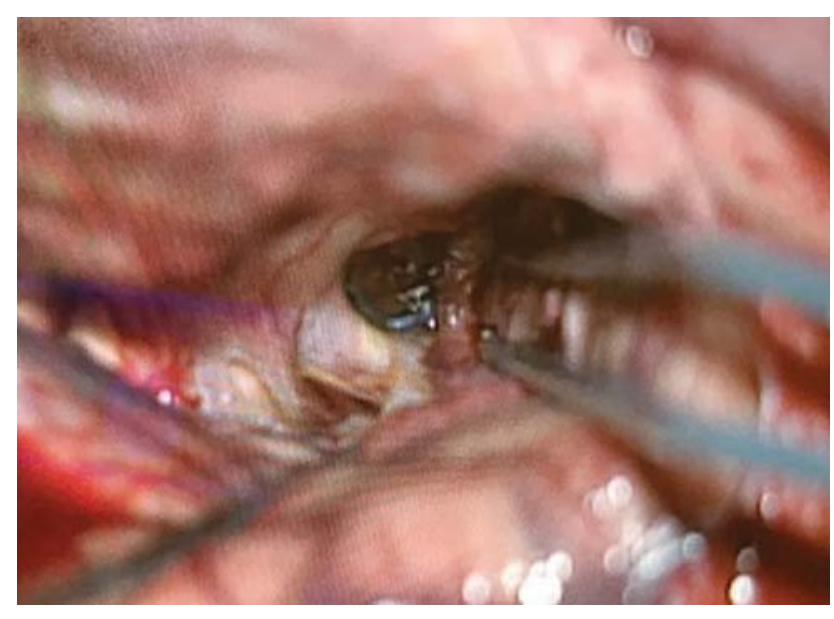

Fig. 4 During microsurgical cisternostomy it could be noticed the presence of an aneurysm clipping (internal carotid artery posterior communicating segment) - Case 2 .

generally cause focal lesions, such as epidural hematomas, brain contusions, and skull fractures. ${ }^{1}$ The neurosurgery procedures for draining these hematomas, if they have significant repercussion, are well established in the literature. The Brain Trauma Foundation Guidelines describe these indications. ${ }^{1,7}$ On the other hand, due to inertial forces, in some cases, there are diffuse injuries, mainly brain swelling, traumatic SAH, diffuse axonal injury (DAI), and subdural hematomas. ${ }^{8}$ These lesions constitute a therapeutic challenging and require a multidisciplinary team for a proper management.

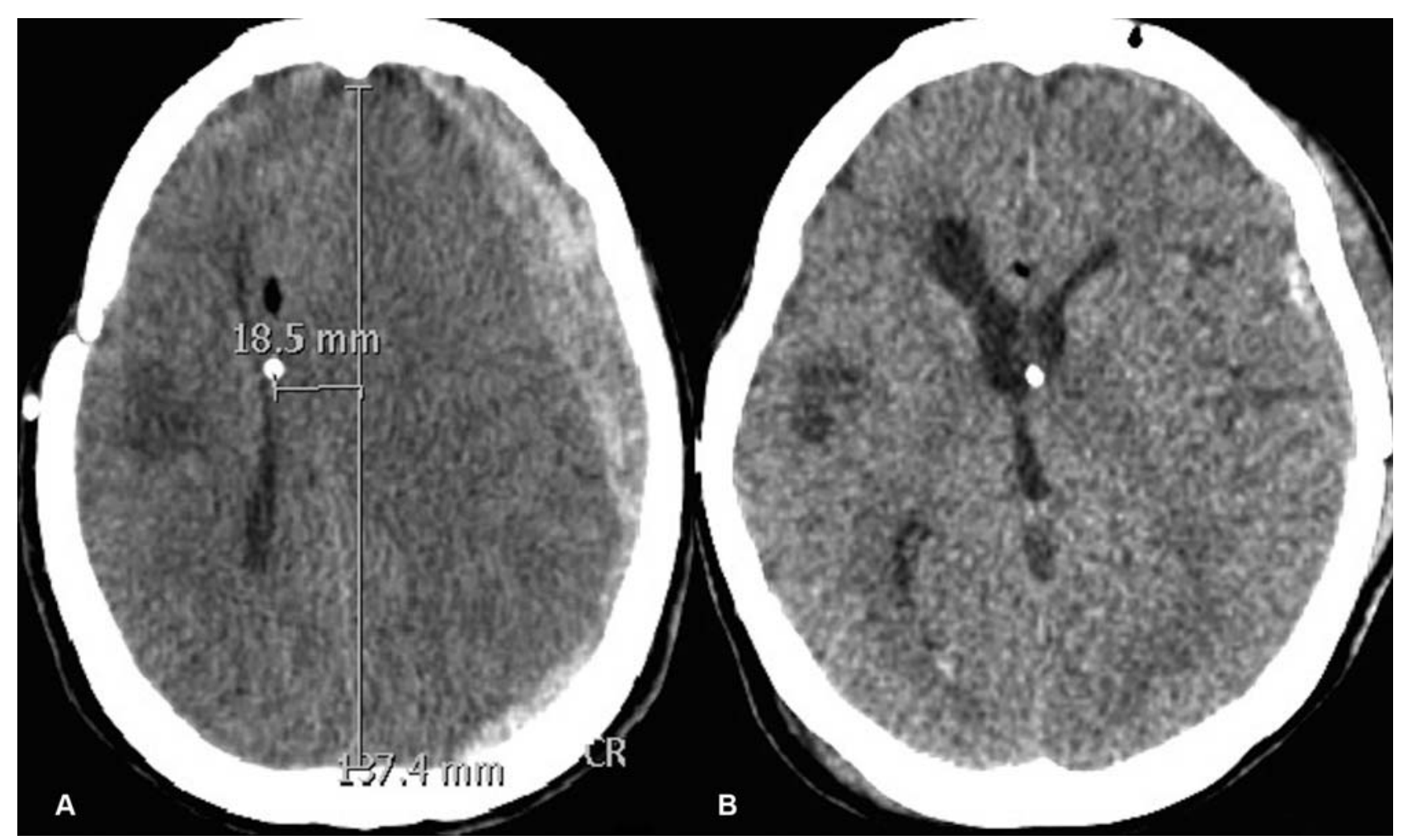

Fig. 3 (A) Preoperative brain computed tomography disclosing huge left subdural hematoma and brain swelling with severe midline shift; (B) 24 hours postoperative brain computed tomography revealing brain swelling and midline deviation reduction. 
For diffuse TBI, DC may be an option for decreasing the raised intracranial pressure associated when there is an important brain swelling and midline shift causing brain herniation. However, many huge trials, such as DECRA and RESCUE-ICP, have demonstrated that this procedure has high morbidity and mortality rates. ${ }^{1,2,9}$ The technique and indications of DC have been extensively described in previous studies; $;^{4,10}$ nevertheless, the outcomes and costs are high, and these patients always require at least one more neurosurgical procedure for cranioplasty.

Recently, a Brazilian study had shown elevated costs associated with DC for TBI. ${ }^{4}$ Patients who do survive generate greater hospitalization costs, and the majority of them will require future hospitalizations for treatment of clinical complications and other procedures, such as ventricular shunts and cranioplasty. Some studies have demonstrated that the real cost of these patients is $\sim 10$ to 15 times greater than the cost of the treatment in the acute phase., , $^{4,12}$

Encephalic hemodynamic is severely altered after skullcap removal, and many complications are associated with this, such as hydrocephalus. In some cases, after DC, a permanent shunt is required in addition to further cranioplasty (with autologous or heterologous bone) to restore hydrodynamics. ${ }^{13}$ Cranioplasty is a surgical procedure that requires another hospitalization after the acute phase and offers some risks, such as infection. Besides, it could be expensive, especially if synthetic prosthesis is used. A national population analysis performed in the United States revealed a mean total cost of U\$ 94,356 , with hospital payments comprising most of this cost at a mean of U\$ 82,680 . $^{14}$

Recent evidence suggests that in trauma, edema formation is also associated with CSF entrance into the brain parenchyma via the low-resistance para-arterial space or decreased interstitial fluid efflux or a combination of the two processes. ${ }^{6}$ There is a hypothesis that the glymphatic removal of excess interstitial fluid decreases new injury, and, therefore, CSF is shifted from the cerebral cisterns to the brain after TBI. ${ }^{6}$ The hydrodynamics of the brain is altered after a severe TBI associated with diffuse lesions due to this mechanism.

Because of these principles, anatomy and physiology of the cisternae were studied ${ }^{4}$ in the context of trauma. Commonly, the basal cisternae opening is a procedure performed in skull base and vascular neurosurgeries. It is useful for brain relaxation, helping to improve CSF flow and brain hydrodynamics. 6,15 In diffuse TBI, the cisterns are usually compressed, and the CSF flow is altered. ${ }^{1,3,16}$ The Marshall Graduation System considers the cisternae status for TBI graduation and mortality estimate. Opening cisterns in a tight brain is a difficult procedure. Nevertheless, after the opening of the interoptic, opticocarotid, and lateral carotid cisternae, the brain become lax. This procedure reverses the cisternal pressure gradient, causing CSF to flow back into the cisterns, thus decreasing the intracranial pressure. $^{6,15}$

Cherian et $\mathrm{al}^{1,3}$ described a case series of cisternostomy for the treatment of TBI, comparing it with DC, and achieved good results. Cisternostomy presented decreased morbidity and mortality when compared with DC. Cisternostomy has a low cost, same surgical duration and better outcomes. Patients will not require additional procedures, as they do after DC: a cranioplasty is always performed, and, in many cases, patients required ventriculoperitoneal shunt to restore brain hydrodynamics. In this protocol, the lamina terminalis is also opened.

After local ethics committee approval and national databank registration, this technique is being performed at our institution for patients with diffuse TBI to whom DC would be classically indicated (considering established protocols for this surgery). Inclusion and exclusion criteria were applied to perform this study, considering age, time from the trauma until the surgery, the presence of severe major internal organ lesions, and family authorization.

These are the initial results of an extensive protocol that is being applied at our institution.

\section{Conclusions}

Cisternostomy was performed in the cases described in the present manuscript as part of this new protocol for the treatment of TBI. A similar study was previously published only by a single center with good outcomes. Patients evolved with a proper functional recovery and did not require further neurosurgical interventions. This technique is an advance in neurotrauma surgery. Low costs, morbidity and mortality are the major benefits of cisternostomy. A case series is being developed at our institution for a better analysis of the results.

\section{Conflict of Interest}

The authors declare that there are no conflicts of interest.

\section{References}

1 Cherian I, Bernardo A, Grasso G. Cisternostomy for traumatic brain injury: pathophysiological mechanisms and surgical technical notes. World Neurosurg 2016;89:51-57. Doi: 10.1016/j. wneu.2016.01.072

2 Badke GL, Araujo JLV, Miura FK, et al. Analysis of direct costs of decompressive craniectomy in victims of traumatic brain injury. Arq Neuropsiquiatr 2018;76(04):257-264. Doi: 10.1590/0004282x20180016

3 Cherian I, Yi G, Munakomi S. Cisternostomy: Replacing the age old decompressive hemicraniectomy? Asian J Neurosurg 2013;8(03): 132-138. Doi: 10.4103/1793-5482.121684

4 Hutchinson PJ, Kolias AG, Timofeev IS, et al; RESCUEicp Trial Collaborators. Trial of Decompressive Craniectomy for Traumatic Intracranial Hypertension. N Engl J Med 2016;375(12):1119-1130. Doi: 10.1056/NEJMoa1605215

5 Cooper DJ, Rosenfeld JV, Murray L, et al; DECRA Trial Investigators; Australian and New Zealand Intensive Care Society Clinical Trials Group. Decompressive craniectomy in diffuse traumatic brain injury. N Engl J Med 2011;364(16):1493-1502. Doi: 10.1056/ NEJMoa1102077

6 Cherian I, Beltran M, Kasper EM, Bhattarai B, Munokami S, Grasso G. Exploring the Virchow-Robin spaces function: A unified theory of brain diseases. Surg Neurol Int 2016;7(Suppl 26):S711-S714

7 Aiolfi A, Benjamin E, Khor D, Inaba K, Lam L, Demetriades D. Brain Trauma Foundation Guidelines for Intracranial Pressure Monitoring: Compliance and Effect on Outcome. World J Surg 2017;41 (06):1543-1549. Doi: 10.1007/s00268-017-3898-6

8 Marmarou A. A review of progress in understanding the pathophysiology and treatment of brain edema. Neurosurg Focus 2007; 22(05):E1. Doi: 10.3171/foc.2007.22.5.2 
9 Hutchinson PJ, Corteen E, Czosnyka M, Mendelow AD, Menon DK, Mitchell P, et al. Decompressive craniectomy in traumatic brain injury: the randomized multicenter RESCUE- icp study (www. RESCUEicp.com). Acta Neurochir Suppl (Wien) 2006;96:17-20

10 Timofeev I, Santarius T, Kolias AG, Hutchinson PJ. Decompressive craniectomy - operative technique and perioperative care. Adv Tech Stand Neurosurg 2012;38:115-136. Doi: 10.1007/978-3-70910676-1_6

11 Pickard JD, Bailey S, Sanderson H, Rees M, Garfield JS. Steps towards cost-benefit analysis of regional neurosurgical care. BMJ 1990;301(6753):629-635. Doi: 10.1136/bmj.301.6753.629

12 Whitmore RG, Thawani JP, Grady MS, Levine JM, Sanborn MR, Stein SC. Is aggressive treatment of traumatic brain injury cost-effective? J Neurosurg 2012;116(05):1106-1113. Doi: 10.3171/2012.1.JNS11962
13 Stiver SI. Complications of decompressive craniectomy for traumatic brain injury. Neurosurg Focus 2009;26(06):E7. Doi: 10.3171/2009.4. FOCUS0965

14 Li A, Azad TD, Veeravagu A, et al. Cranioplasty Complications and Costs: A National Population-Level Analysis Using the MarketScan Longitudinal Database. World Neurosurg 2017;102:209-220. Doi: 10.1016/j.wneu.2017.03.022

15 Cherian I, Grasso G, Bernardo A, Munakomi S. Anatomy and physiology of cisternostomy. Chin J Traumatol 2016;19(01): 7-10

16 Masoudi MS, Rezaee E, Hakiminejad H, Tavakoli M, Sadeghpoor T. Cisternostomy for Management of Intracranial Hypertension in Severe Traumatic Brain Injury; Case Report and Literature Review. Bull Emerg Trauma 2016;4(03):161-164 